\title{
Radioimmunoassay of serum myoglobin in neuromuscular diseases
}

\author{
HÅKAN ASKMARK, PER OLOF OSTERMAN, LARS-ERICROXIN, \\ AND PER VENGE \\ From the Departments of Neurology and Clinical Chemistry, University Hospital, Uppsala, Sweden
}

SUMMARY Radioimmunoassay of serum myoglobin was performed in 85 patients with muscular symptoms. Elevated levels were found in $93 \%$ of patients with myogenic myopathy, in $54 \%$ with myasthenia gravis and in 50\% with neurogenic myopathy. All 11 patients with polymyositis had elevated myoglobin concentrations. In six of seven patients with polymyositis, who were followed up with repeated determinations, a clear relationship between myoglobin levels and clinical course was found. In general serum myoglobin seemed to be a more sensitive indicator of muscle disease than creatine kinase.

Myoglobin (Mb) is a low molecular weight protein which is considered to be located solely in skeletal and myocardial muscle, and increased leakage of $\mathrm{Mb}$ into the circulation should be a specific indicator of muscle cell damage.

$\mathrm{Mb}$ was first recognised in the sera of patients with polymyositis in $1971 .^{1}$ However, following the recent introduction of radioimmunoassays for detection of $\mathrm{Mb}$ this protein has also been detected in low concentrations in the sera of healthy individuals. ${ }^{23}$ Radioimmunoassay of $\mathrm{Mb}$ has proved useful in the diagnosis of myocardial infarction $^{45}$ and myopathy. ${ }^{6-8}$ The purpose of the present study was to investigate further the value of serum $\mathrm{Mb}$ assay in neuromuscular diseases.

\section{Patients and methods}

Patients The study was made on 85 patients (44 men and 41 women between 20 and 80 years of age) admitted to the Department of Neurology, Uppsala University Hospital. Eleven of them had polymyositis, eight muscular dystrophy, nine unclassified myogenic myopathy, 28 myasthenia gravis, one Eaton-Lambert's syndrome, and 12 neurogenic myopathy. The other 16 patients had muscular aching, but no convincing clinical or laboratory signs of neuromuscular disease. The diagnoses were based on the clinical picture, EMG, and serum enzyme determinations (CK, ASAT, ALAT, LD); in patients with myogenic myopathy

Address for reprint requests: Dr Håkan Askmark, Department of Neurology, University Hospital, S-750 14 Uppsala, Sweden.

Accepted 26 August 1980 muscle biopsies were also performed. The criteria of Bohan and Peter $^{9}$ were used for the diagnosis of polymyositis and the diagnosis of myasthenia gravis was confirmed by the typical case history, a positive response to edrophonium, single fibre EMG (by Stålberg ${ }^{10}$ ) and by determination of acetylcholine receptor antibodies.11 All patients had normal serum creatinine levels and none showed clinical signs of liver disease.

Methods Serum $\mathrm{Mb}$ was assayed by means of a solid-phase radioimmunoassay described earlier.12 Each serum sample was assayed in duplicate. The within-day variation was $8 \%$ (coefficient of variation). The normal values for serum $\mathrm{Mb}$, in a reference material of 99 blood donors of ages 20-62 years, was $35.7 \mu \mathrm{g} / 1 \pm 20.8$ (mean $\pm 2 \mathrm{SD}$ ) for women and $50.6 \mu \mathrm{g} / 1 \pm 39 \cdot 6$ (mean \pm 2 SD) for men. ${ }^{12}$ Serum CK determinations were performed at the routine laboratory. The upper normal limit $(+2$ SD) was $2.5 \mu \mathrm{kat} / 1\left(2.5 \mu \mathrm{mol}\right.$ per second per litre, $\left.\mu \mathrm{mol} \mathrm{s}^{-1} \mathrm{l}^{-1}\right)$.

\section{Results}

The serum concentrations of $\mathrm{Mb}$ and the number of patients with elevated $\mathrm{Mb}$ and serum CK levels are given in fig 1 and table 1 , respectively. The highest incidence of elevated $\mathrm{Mb}$ values was found in the group of patients with myogenic myopathy. Thus, 26 out of 28 patients $(93 \%)$ with myogenic myopathy had raised Mb levels. Elevated CK values were found in $17(61 \%)$ of these patients. The highest $\mathrm{Mb}$ values were found among patients with polymyositis. All 11 patients with polymyositis had elevated $\mathrm{Mb}$ concentrations ranging between 94 and $1972 \mu \mathrm{g} / 1$ (mean 701). Raised CK levels were noted in seven of the 


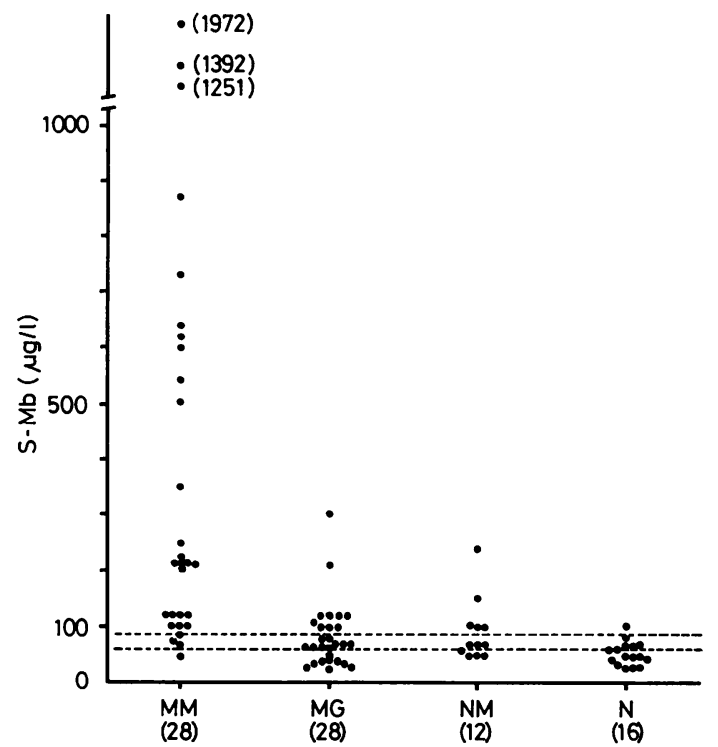

Fig 1 Serum myoglobin concentrations in patients with myogenic myopathy (MM), myasthenia gravis (MG), neurogenic myopathy (NM), and in patients with muscular ache but no evidence of neuromuscular disease (N). Upper normal limits for men and women indicated (- - - ).

patients with polymyositis. At the start of the study three of the patients with polymyositis were being treated with steroids and these patients had normal CK levels.

Serum $\mathrm{Mb}$ was determined on several occasions during a period of 6-33 months in seven patients with polymyositis. In six of them there was a clear relation between $\mathrm{Mb}$ levels, CK levels and clinical course as exemplified in figs 2 and 3. The $\mathrm{Mb}$ values declined within a few weeks after institution of steriod therapy, slightly prior or parallel with the clinical improvement, and in case of deterioration of the disease there was a rapid increase in serum $\mathrm{Mb}$. In one patient with polymyositis there were only minor fluctuations of $\mathrm{Mb}$ and $\mathrm{CK}$ levels and there was no obvious relation between these fluctuations and the clinical course. However, this patient had had polymyositis for more than two years and had been treated with steroids for seven months at the start of the study, at which time he also had severe muscle atrophy.

In the group with myogenic myopathy, only two patients (one man with distal myopathy of the Welander type and one woman with an unclassified myopathy) had normal $\mathrm{Mb}$ levels, and these patients also had normal CK levels.

Raised $\mathrm{Mb}$ concentrations were noted in 15 of the 28 patients with myasthenia gravis and two of the patients with myasthenia gravis had elevated CK levels. Among the 15 myasthenia gravis patients with elevated serum $\mathrm{Mb}$, six had mild generalised myasthenia (Osserman 2A). Nine of them had severe generalised myasthenia (Osserman 2B, 3, 4), although at the time of the study only four had disabling symptoms. Thymectomy had been performed in 10 of the 15 patients and thymoma had been found in five cases. In 11 of the 15 patients acetylcholine receptor antibodies (mean 5.33 arbitrary units) were demonstrated and eight patients also had antibodies against striated muscle. Eight of the patients were treated with steroids. Normal $\mathrm{Mb}$ levels were found in 13 of the patients with myasthenia gravis. In this group two patients had severe generalised myasthenia (Osserman $2 \mathrm{~B}$ and 3 , respectively), but only one patient had disabling symptoms at the time of the study. The other 11 patients had mild generalised myasthenia. Thymectomy had been performed in 11 of the 13 patients and thymoma had been found in one case. Acetylcholine receptor antibodies

Table 1 Incidence of elevated serum $M B$ and $C K$ levels in different patient groups

\begin{tabular}{llll}
\hline Condition & Number of patients & $\begin{array}{l}\text { Number of patients with } \\
\text { elevated Mb }(\%)\end{array}$ & clevated CK (\%) \\
\hline I Myogenic myopathy & 28 & $26(93)$ & $17(61)$ \\
$\quad \begin{array}{l}\text { Polymyositis } \\
\text { Muscular dystrophy }\end{array}$ & 11 & $11(100)$ & $7(64)$ \\
$\quad$ Myogenic myopathy, unclassified & 9 & $7(87)$ & $5(62)$ \\
II Diseases with disturbed & & $8(89)$ & $5(55)$ \\
$\quad$ neuromuscular transmission & 29 & $15(52)$ & $2(7)$ \\
$\quad \begin{array}{l}\text { Myasthenia gravis } \\
\quad \text { Eaton-Lambert's syndrome }\end{array}$ & 1 & $15(54)$ & $0(0)$ \\
III Neurogenic muscular atrophy & 12 & $0(0)$ & $3(25)$ \\
IV Patients with muscular ache but no & & $6(50)$ & $0(0)$ \\
\hline
\end{tabular}



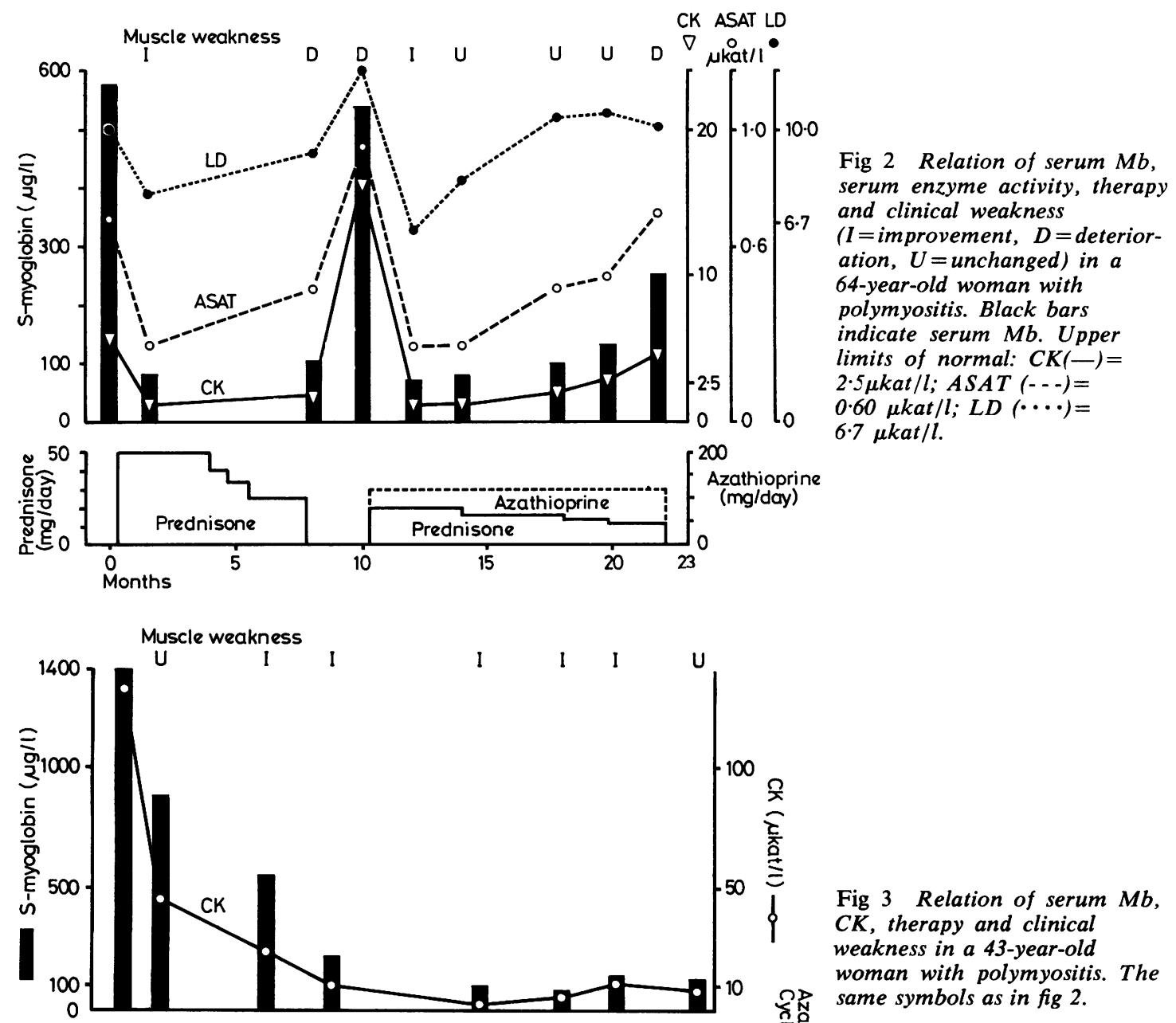

Fig 3 Relation of serum $M b$, $C K$, therapy and clinical weakness in a 43-year-old woman with polymyositis. The same symbols as in fig 2.

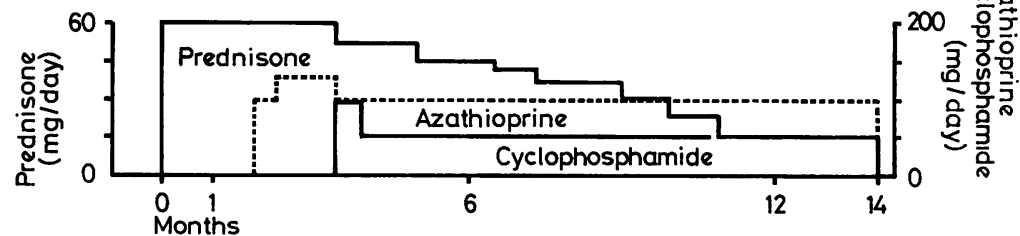

(mean 2.47 arbitrary units) were demonstrated in eight patients and one patient also had antibodies against striated muscle. One patient was treated with steroids.

Six of the 12 patients with neurogenic myopathy had elevated $\mathrm{Mb}$ levels and three patients had elevated serum CK. The group with elevated $\mathrm{Mb}$ levels consisted of three patients with motor neuron disease, two with GuillainBarré syndrome and one with Charcot-Marie-
Tooth disease. One patient with motor neuron disease, one with diabetic polyneuropathy and four with mononeuropathy had normal $\mathrm{Mb}$ values.

Elevated $\mathrm{Mb}$ concentrations were noted in two of the 16 patients who complained of muscular ache but who presented no convincing clinical or laboratory signs of neuromuscular disease. All patients in this group had normal CK levels.

The simultaneously estimated levels of $\mathrm{Mb}$ and 
Table 2 Simultaneous determination of serum $M B$ and $C K$ in 69 patients with neuromuscular diseases

\begin{tabular}{lll}
\hline & $C K$ & $C K$ \\
& normal & $\begin{array}{l}C K \\
\text { elevated }\end{array}$ \\
\hline Mb elevated & 27 & 20 \\
Mb normal & 20 & 2 \\
\hline
\end{tabular}

CK were compared (table 2) in all 69 patients with neuromuscular diseases (groups I-III, table 1). Mb was elevated in 47 patients and $\mathrm{CK}$ in 22 patients. Only in two cases were normal $\mathrm{Mb}$ levels found when $\mathrm{CK}$ was raised.

\section{Discussion}

Several serum enzymes such as aldolase, ASAT, ALAT and LD are increased in myopathies, but since these enzymes also reside in other tissues than muscle, their use in the diagnosis of myopathy is limited. Estimation of $\mathrm{CK}$ in serum is used widely in the diagnosis of muscle disease because of its high specificity to muscle tissue. However, CK is also present outside muscle and the serum CK level may be elevated in persons with no evidence of myopathy. ${ }^{13} \mathrm{Mb}$ is considered to be located solely in skeletal and myocardial muscle, and increased serum levels of this protein, in the absence of impaired glomerular filtration and impaired liver function, ${ }^{12}$ should be specific for disease or damage to muscle tissue. Dynamic muscular exercise seems to cause only minor variations in serum $\mathrm{Mb}$ levels. ${ }^{12}$

In our study, 26 of 28 patients (93\%) with myogenic myopathy had raised Mb levels. This group included 11 patients with polymyositis and in all of these the serum $\mathrm{Mb}$ was increased. This finding is in accordance with the report of Miyoshi et al, ${ }^{7}$ who investigated 20 patients with myogenic myopathy (six with polymyositis and 14 with Duchenne's muscular dystrophy), and found elevated $\mathrm{Mb}$ levels in all of them. Hische and Van der Helm reported that the serum $\mathrm{Mb}$ levels were raised in $54 \%$ of patients with neuromuscular diseases. ${ }^{8}$ Eight of nine patients with untreated polymyositis had elevated $\mathrm{Mb}$ levels and such an increase was found in $74 \%$ of all the patients with myogenic myopathy. Using a solid-phase radioimmunoassay very similar to ours, Nishikai and Reichlin ${ }^{6}$ noted increased serum $\mathrm{Mb}$ in only $50 \%$ of patients with polymyositis and in $38 \%$ with muscular dystrophy. The use of different normal values of serum $\mathbf{M b}$ might conceivably contribute to this discrepancy, but it is difficult to explain the difference between their results and ours. Contrary to Nishikai and Reichlin we have not used the same normal values for men and women, as there is a significant difference in serum $\mathrm{Mb}$ levels between healthy men and women. ${ }^{12}$ In polymyositis one other explanation might be a difference in the treatment of the patients at the time of the sampling.

The results of the present investigation indicate that radioimmunoassay of serum $\mathbf{M b}$ is a more sensitive method for detection of muscle disease than determination of CK. Only two of 28 patients with myogenic myopathy had normal Mb levels, whereas normal serum CK was noted in 11 patients in this group. Consequently, the finding of a normal serum $\mathrm{Mb}$ does not exclude, but considerably reduces the probability of a myogenic myopathy.

Nishikai and Reichlin ${ }^{6}$ noted elevated $\mathrm{Mb}$ levels in five of 13 patients $(38 \%)$ with myasthenia gravis and in our study 15 of 28 patients (54\%) with this disease had raised Mb levels. In myasthenia gravis elevated CK levels are seldom found (in our material four of 83 patients with myasthenia gravis had elevated serum CK). This discrepancy between $\mathrm{Mb}$ and $\mathrm{CK}$ levels in patients with myasthenia gravis indicates a selective leakage of low molecular weight protein from the muscle cell. There were more patients with severe forms of myasthenia (Osserman 2B, $3,4)$ in the group with elevated $\mathrm{Mb}$ and this group had also higher concentrations of acetylcholine receptor antibodies. We found no distinct relationship, however, between $\mathrm{Mb}$ levels and the clinical condition at the time of sampling

In conclusion radioimmunoassay of serum $\mathrm{Mb}$ appears to be valuable as a supplementary tool to detect the presence of a myopathy and also seems useful for evaluating the status and therapeutic result in polymyositis. Serum Mb seems to be a more sensitive indicator of muscle disease than $\mathrm{CK}$, and a normal serum $\mathrm{Mb}$ level in a patient not treated with steroids will considerably decrease the probability of a myogenic myopathy. Further study is needed to find out whether $\mathrm{Mb}$ determinations might also be of practical value in myasthenia gravis.

The skilful technical assistance of Miss Kerstin Lindblad is greatly appreciated.

\section{References}

1 Kagen LJ. Myoglobinemia and myoglobinuria in patients with myositis. Arthritis Rheum 1971; 14: 457-64.

2 Stone MJ, Willerson JT, Gomez-Sanchez CE. Waterman MR. Radioimmunoassay of myo- 
globin in human serum. J Clin Invest 1975; 56: 1334-9.

3 Rosano TG, Kenny MA. A radioimmunoassay for human serum myoglobin: Method development and normal values. Clin Chem 1977; 23: 69.-75.

4 Rosano TG, Sanders LA, Johnson ES, Kenny MA, Clayson KJ, Strandjord PE. Myoglobin concentrations and muscle-enzymes activities in serum after myocardial infarction and cardiac arrhythmia. Clin Chem 1977; 23:868-70.

5 Stone MJ, Waterman MR, Harimoto D et al. Serum myoglobin level as diagnostic test in patients with acute myocardial infarction. $\mathrm{Br}$ Heart J 1977; 39:375-80.

6 Nishikai M, Reichlin M. Radioimmunoassay of serum myoglobin in polymyositis and other conditions. Arthritis Rheum 1977; 20:1514-8.

7 Miyoshi K, Saito S, Kawai H et al. Radioimmunoassay for human myoglobin: methods and results in patients with skeletal muscle or myo- cardial disorders. J Lab Clin Med 1978; 92:34152.

8 Hische EAH, Van der Helm HJ. The significance of the estimation of serum myoglobin in neuromuscular diseases. J Neurol Sci 1979; 43:243-51.

9 Bohan A, Peter JB. Polymyositis and dermatomyositis. N Engl J Med 1975; 292:344-7.

10 Stålberg E, Trontelj JV. Single Fibre Electromyography. Surrey: Mirvalle Press Limited, 1979: 1-244.

11 Lefvert AK, Bergström K, Matell G, Osterman PO, Pirskanen R. Determination of acetylcholine receptor antibody in myasthenia gravis. Clinical usefulness and pathogenetic implications. $J$ Neurol Neurosurg Psychiatry 1978; 41:394-403.

12 Roxin L-E, Venge $\mathbf{P}$, Friman $\mathbf{G}$, Hällgren $\mathbf{R}$. Radioimmunoassays of human myoglobin in serum and urine. Scand J Clin Lab Invest 1979; 39:37-46.

13 Nevins MA, Saran M, Bright $M$, Lyon LJ. Pitfalls in interpreting serum creatine phosphokinase activity. JAMA 1973; 224:1382-7. 